\title{
Development of Ultra-high Pressure Cooling and Quick Freezing Device Based on Hydraulic Transmission
}

\author{
Min $\mathrm{Li}^{1,2^{*}}$, Changming Ling ${ }^{1,2^{*}}$, Biao $\mathrm{Ye}^{1,2}$, Junhao Cai ${ }^{1,2}$, Wenzhen Wang ${ }^{1,2}$, and Junfeng $\mathrm{Li}^{1,2}$ \\ ${ }^{1}$ Guangdong Ocean University ,Shenzhen Institute of Guangdong Ocean University, 518108,Guangdong Shenzhen, China \\ ${ }^{2}$ Guangdong Ocean University, College of mechanical and power engineering Guangdong Zhanjiang, 524088, China
}

\begin{abstract}
Based on the theory of high pressure supercooling and pressure relief quick freezing, the ultrahigh pressure instantaneous freezing device is developed. This device can break through the limitations of existing ultra-high pressure device design. Through the new hydraulic transmission design, It can complete fast pressurization, fast pressure relief and achieve continuous work. The matching of whole systems under certain load conditions, hydraulic transmission system, refrigeration system, pressure vessel and pressure relief system has been completed. The device can realize the whole process of ultra-high pressure quick freezing from food feeding, pressure cooling, pressure relief instant freezing and semi-automatic food discharging. Compared with the conventional same-capacity quick-freezing device, the energy consumption of the instantaneous freezing device under the design condition is only $24.52 \%$ of that of the traditional quick-freezing device, which greatly saves energy consumption. From the perspective of application, the design concept of ultra-high pressure quick-freezing device is perfected and the practical process of ultrahigh pressure quick-freezing is advanced.
\end{abstract}

\section{Introduction}

In the process of freezing, the ice crystals are unevenly arranged due to uneven internal temperature [1]. Besides, large ice crystals will damage the organization and structure of materials and greatly reduce the quality of food [2]. Previous studies have shown that rapid freezing can make ice crystals small and uniform [3].At present, liquid nitrogen spray freezing is regarded as overspeed freezing, but for food with thick, large and high moisture content, it will cause cracking or low-temperature fracture due to overspeed freezing [4]. The existing research shows $[5,6]$ that, if the pressure parameters are introduced during the freezing process, the higher the pressure, the lower the freezing point of water, the freezing point of water at $200 \mathrm{Mpa}$ is $-21.99^{\circ} \mathrm{C}$. After being pressurized the high-moisture food to $200 \mathrm{Mpa}$, the food is cooled down to $-20^{\circ} \mathrm{C}$, and then the pressure is rapidly reduced. The food at $-20^{\circ} \mathrm{C}$ becomes extremely unstable supercooling state, producing a large number of extremely fine ice crystals in an instant, which are evenly distributed in all parts of the frozen products, greatly reducing the freezing stress, obtaining the frozen food with high quality, and realizing ultra-high pressure instantaneous freezing. Ultra-high pressure instantaneous freezing can better solve the problems of water transfer and ice crystal frost heave caused by temperature difference in the freezing process [7]. Although some theories have shown that this kind of ultra-high pressure instantaneous freezing is feasible, a design device that can achieve rapid pressure gain and instantaneous pressure relief has not been obtained, so the ultra-high pressure instantaneous freezing device has no real continuous working system until now

The existing ultra high pressure processing (HPP) equipment [8] is mainly used for sterilization and nonheat treatment of food. Moreover, the direct-pressure type ultra-high pressure processing equipment mainly has problems such as small working volume, slow pressurization speed, and inability to complete instantaneous pressure relief after ultra-high pressure cooling [8]. Based on this, a semi-automatic ultra-high pressure quick-freezing device was designed by using the principle of cooling food under ultra-high pressure and instantaneous freezing under unloading pressure. After designing and matching the refrigeration system, hydraulic system and pressure relief system, the device can realize the instantaneous freezing of food, and solve the problem of nutrition loss caused by the freezing process of food. Through the comparison and analysis of energy consumption and performance with the same capacity of atmospheric quick-freezing device, it is intended to provide theoretical basis for the design calculation of new ultra-high pressure quick-freezing device, and provide hardware support for the design of new ultra-high pressure quick-freezing food technology.

\section{Introduction to the design plan}

The ultra-high pressure quick-freezing device is the necessary hardware to realize the ultra-high pressure quick-freezing process. The device must have the

$\overline{\text { Corresponding author:lim@gdou.edu.cn, }}$ ling-cm@163.com 
functions of refrigeration, pressurization and pressure relief, and the material must be frozen and moved in and out smoothly. Refrigeration systems, hydraulic systems, pressure relief and material entry and exit systems must be matched to achieve these functions. The schematic diagram of the structure of this design is shown in figure 1. The whole device consists of three parts, the refrigeration part, the hydraulic part and the pressure relief part, corresponding to three functions, cooling, pressurization and pressure relief instantaneous freezing.

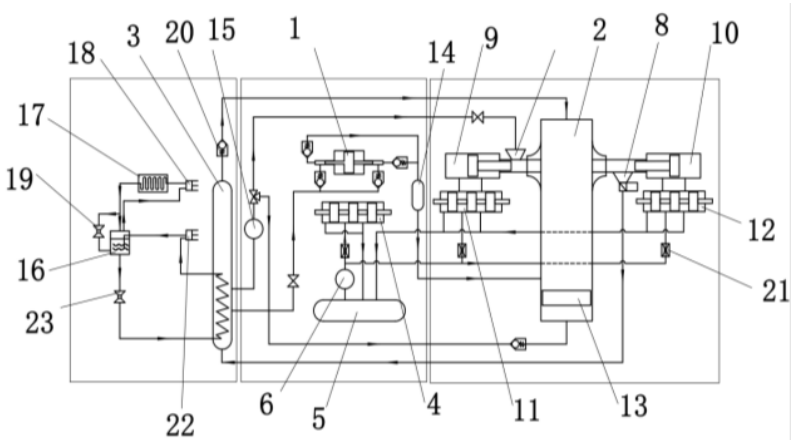

1- Pressure cylinder; 2- Ultra-high pressure reaction kettle; 3 Ethanol tank; 4- First/three-position four-way electromagnetic reversing valve; 5-Hydraulic oil storage drum; 6-First hydraulic pump; 7-Feed port; 8-Discharge port; 9-Imported piston cylinder; 10-Outlet piston cylinder; 11-The second three four-way electromagnetic reversing valve; 12 - Third/three fourway electromagnetic directional valve; 13 -Free piston; 14Accumulator; 15-Second hydraulic pump; 16-Intercooler; 17Condenser; 18-Advanced compressor; 19-Throttle valve I; 20One-way valve; 21 -Speed regulating valve; 22 -low compressor; 23-Throttle valve II.

Fig.1. Schematic diagram of structure

\subsection{Working principle of the device and material handling process}

A refrigeration system is required to achieve quick freezing, Food should be supercooled to $-20^{\circ} \mathrm{C}$, and the evaporation temperature of refrigeration is low. Doublestage compression refrigeration system is adopted, with R22 as refrigerant and ethanol as refrigerant carrier. Followed by the hydraulic system, low-temperature hydraulic oil (l-hv) is adopted as the working medium, the hydraulic system consists of a pressurized cylinder, ultra-high pressure reaction kettle, ethanol liquid storage barrel, first/three-position four-way electromagnetic reversing valve, hydraulic oil storage barrel and the first hydraulic pump. The opposite sides of the high-pressure reaction kettle are respectively provided with feeding port and discharging port, and the materials are vacuumpacked and then put into the ultra-high pressure reaction kettle from the material port. The material is transported into the ultra-high pressure reaction kettle by the flow of the low-temperature ethanol liquid, and the material is deposited on the upper surface of the free piston under its own gravity. The material is pressurized and cooled by ethanol liquid with pressure of $200 \mathrm{MPa}$ and temperature of $-35^{\circ} \mathrm{C}$ in the ultra-high pressure reaction kettle. After the material is cooled to a subcooling state with a center temperature of $-20^{\circ} \mathrm{C}$, the pressure relief device is opened, and the pressure in the ultrahigh pressure reaction kettle is instantaneously relieved to atmospheric pressure, and the material in the supercooled state is instantaneously frozen. At this point, the free piston moves up, pushing the material up, the frozen food is pushed to the outlet, and the outlet piston is opened. The ethanol liquid transports the material to the discharge port to complete the whole material processing process.

\subsection{Workflow of hydraulic system [9]}

Similarly, as shown in Figure 1, the pressurized zone of the system consists of a hydraulic oil circuit and a high pressure ethanol circuit. In the hydraulic oil circuit, the motor-driven hydraulic pump absorbs oil in the hydraulic oil storage tank, and the pressure oil outputted by the hydraulic pump is adjusted by the speed regulating valve, and then enters the left piston chamber of the booster cylinder through the left position of the three-position four-way electromagnetic reversing valve. Meanwhile, the hydraulic oil in the right piston cavity of the pressurized cylinder flows back to the hydraulic oil storage tank through the right position of the reversing valve. The piston of the pressurized cylinder goes right under the action of pressure oil. At this time, the plunger of the pressurized cylinder pressurizes the ethanol liquid in the right plunger cavity. The effective area ratio on both sides of the pressurized cylinder is $25: 1$. According to PASCAL's principle, the liquid pressure ratio between the piston cylinder and the plunger cylinder is 1:25 [10]. The ultra-high pressure anhydrous ethanol liquid flows through the check valve and the accumulator to the ultrahigh pressure reaction kettle. At the same time, the piston in the pressurized cylinder travels to the right pole, and the ethanol liquid passes through the check valve into the plunger chamber on the left side. The threeposition four-way electromagnetic reversing valve is reversing, and the hydraulic oil is pressurized by the hydraulic pump to the right piston chamber in the pressurized cylinder. The original left piston cavity hydraulic oil flow back to the hydraulic oil storage tank through the three-position four-way electromagnetic reversing valve, and the pressurized cylinder piston left row. This reciprocating produces a continuous ultra-high pressure ethanol fluid. If the three-position four-way electromagnetic reversing valve is in the neutral position (the valve plug blocks the inlet and outlet ports), then the piston of the pressurized cylinder stops moving, and all the hydraulic oil output from the hydraulic pump flows back to the hydraulic oil storage tank through the middle position of the reversing valve. While the ultra-high pressure ethanol solution continuously pressurizes the ultra-high pressure reaction kettle, the hydraulic pump pressurizes the piston cavity of the pressurized cylinder at the left and right ends of the ultra-high pressure reaction kettle. The three-position four-way electromagnetic directional reversing valve controls the piston to dead point, and serves as the end cover for the inlet and outlet of the materials of ultra-high pressure reaction kettle. 


\subsection{Working process of ultra-high pressure vessels and principle of materials entering and leaving [11]}

The material is placed in the material input port at the left end of the ultra-high pressure reaction kettle, which is pushed by the piston and transported by ethanol liquid into the ultra-high pressure reaction kettle. At this time, the pipeline at the bottom of the reactor is closed, and the free piston has no thrust. It is at the bottom of the reactor under the action of gravity, and the material is placed on the surface of the free piston, which is pressurized and cooled by $200 \mathrm{MPa}$ and $-35^{\circ} \mathrm{C}$ ethanol liquid. When the material is cooled to $-20^{\circ} \mathrm{C}$, the three-position four-way electromagnetic reversing valve of the hydraulic system is closed to prevent the replenishment of ethanol in the ultra-high pressure reaction kettle. Since the liquid outlet pipeline of the ultra-high pressure reaction kettle is connected with the liquid storage bucket, the ultra-high pressure reaction kettle completes pressure relief in a moment and the material is frozen. The sealing piston is controlled to open the import and export of materials through the three-position four-way electromagnetic reversing valve on the left and right sides of the ultrahigh pressure reaction kettle. The valve of the bottom line of the ultra-high pressure reaction kettle is opened, and the free piston is pressurized by the hydraulic pump to slowly raise the material, and the high-speed fluid is sprayed from left to right at the material inlet and outlet to take away the material. The material is sent out of the system through the material separator, and the ethanol liquid returns to the storage barrel of the ethanol liquid.

\subsection{Selection of sealing method for ultra high pressure system}

The system uses ultra-high pressure ethanol liquid to pressurize the material. The connection of the pipeline and the pressure bearing capacity of the vessel during the design process are the biggest limitations of the current ultra-high pressure production process. The following is a brief description of the selection of the pressure line and the connection method.

\subsubsection{Selection of ultra-high pressure steel pipe and pipe connection}

According to the size parameters of steel pipes used in industrial installations and the steel pipe specifications in the standard for ultrahigh pressure pipe fittings with nominal pressure of $294.2 \mathrm{Mpa}\left(\mathrm{Pg}=3000 \mathrm{~kg} / \mathrm{cm}^{2}\right)$, the nominal diameter of ultra-high pressure pipe fittings with nominal diameter of $32 \mathrm{~mm}$ is selected in combination with the actual needs. The outer diameter $\times$ wall thickness is $78 \times 23, \mathrm{~K}=$ outer diameter/inner diameter $=2.44$, the design pressure is $294.2 \mathrm{Mpa}$, and the steel brand number is $40 \mathrm{CrNi} 2 \mathrm{MoA}$.

The pipe is connected by a flanged tapered washer. The connection diagram is shown in figure 2 .
The contact surface of the two parts to be sealed by the connection mode has different angles and relies on the flange to make them close contact.

The contact surfaces made are uniform line contacts, the contact surfaces having different hardnesses, wherein the less rigid contact members are slightly deformed, so that the seal is always reliable when the force that causes the close contact between the two is greater than the working pressure of the medium.

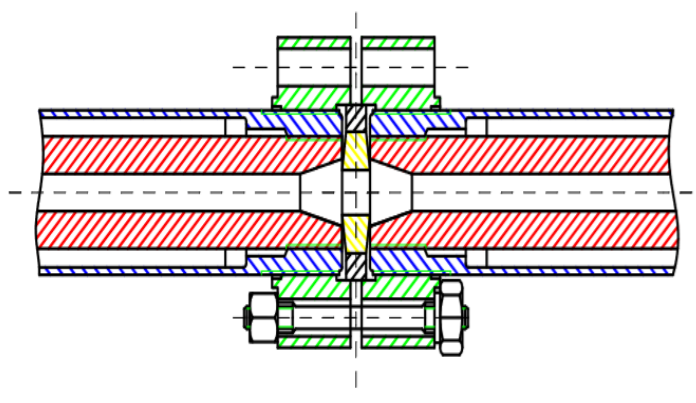

Fig. 2 schematic diagram of pipeline flange connection

\subsubsection{End cover sealing}

The end cover is sealed by Bridgman, as shown in figure 3. Bridgman seal is a self - sealing structure. The gasket is compressed by internal pressure, thus forming a selfsealing, so the higher the internal pressure, the better the sealing effect. The sealing method is simple in structure and does not need to be processed by special sealing parts with high requirements, so it is convenient for processing, low manufacturing cost and convenient for disassembly.

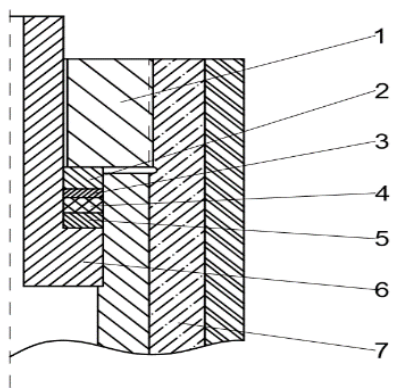

1-- tighten the top cover; 2 - pressure ring;3 - pad ring;4 gasket;5 - pad ring;6-- raised shoulder cover; 7 - the cylinder cover

Fig. 3. Schematic diagram of bridgman sealing

\subsubsection{Ultra-high pressure reaction kettle temperature measurement casting filler wire method}

In order to detect the temperature in the ultra-high pressure reaction kettle in real time, it is necessary to connect the thermocouple in the cylinder wall of the ultra-high pressure reaction kettle with the lead wire. The sealing structure of the lead hole needs electrical insulation and has a strong pressure bearing capability. The structure of tapered lead sealing head is adopted, 
and the steel cone body with ivory hoop is inserted into the cylinder body and the orifice seat. Electric current is introduced along the wire connected with the vertebral body. The tightness between the vertebral body and the orifice is achieved by self-tightening. This structure can be used under a pressure of less than $300 \mathrm{MPa}$, and higher pressure will cause the ivory hoop to be crushed. At present, the insulation sleeve in this structure has been made of laminated baklava, rubber, plastic, plexiglass, etc. according to different conditions. The schematic diagram is shown in figure 4 .

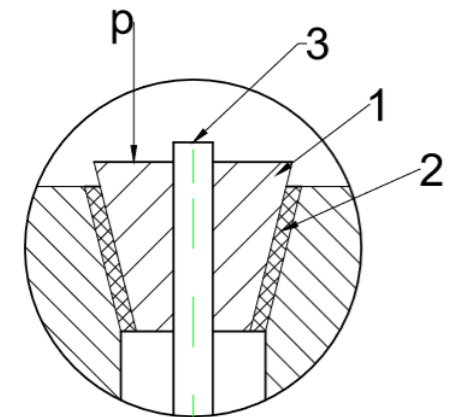

1 - steel cone;2 - ivory hoop;3 - conductor

Fig. 4 Tapered lead seal

\subsubsection{End connection of ultra-high pressure reaction kettle}

The connection structure between the cylinder and the end of the ultrahigh pressure vessel is an important part of the design of the ultrahigh pressure vessel. Under ultra-high pressure, the bolt load is very large, so that the bolt diameter is very large, a lot of number, heavy flange, so the traditional bolt-and-flange structure is abandoned in the structural design. The toothless clamp connection commonly used in ultra-high pressure vessels is adopted, and the flat top view of the clamp is shown in figure5.

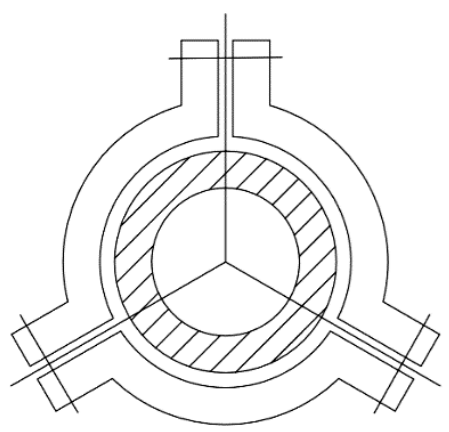

Fig.5 Top view of clamp

\subsection{Matching of refrigeration system}

The refrigeration system adopts steam compression refrigeration system. The required cooling capacity is calculated by designing a certain quick-freezing capacity, and then the required refrigeration system and the type and specification of each equipment are designed or selected. In the design, the evaporator is arranged in the ethanol storage tank to cool the ethanol directly, and the material is cooled by the forced convection of ethanol.
The surface of the cryogenic device needs to be wrapped with insulation material to prevent loss of cold volume.

\section{Typical calculation in case design}

\subsection{Calculation of hydraulic pump pressurizing system[12]}

\subsubsection{Calculation of hydraulic pump working pressure, flow rate and motor power}

Suppose an ultra-high pressure instantaneous freezing device with a quick-freezing capacity of 80 litres is designed, and the ultra-high pressure reaction kettle has a volume of 100 litres.

The matching of the radius of the large and small piston heads in the piston cylinder can better realize the pressure transfer, so the radius of the large and small piston heads in the piston cylinder are $250 \mathrm{~mm}$ and $50 \mathrm{~mm}$ respectively in this design. Then the area ratio of the piston at both ends is 25 . The system working pressure is set as required to $200 \mathrm{MPa}$, and the pressure required for the large piston is $8 \mathrm{MPa}$. In order to make the system work under looser conditions, the working pressure of the hydraulic oil pump is selected to be $10 \mathrm{Mpa}$ (greater than $8 \mathrm{MPa}$ ), and the type is inclined disc plunger pump. Working parameters of the pump: working pressure $\mathrm{P}=10 \mathrm{Mpa}$, displacement $\mathrm{V}=150 \mathrm{ml} / \mathrm{min}$, rotation speed $\mathrm{n}=950 \mathrm{r} / \mathrm{min}$, volumetric efficiency $\eta v=95 \%$. Then the actual flow rate and motor power are calculated as:

$$
\begin{gathered}
\mathrm{q}_{v}=\mathrm{V} * \mathrm{n} * \mathrm{\eta}_{v}=150 * 10^{-3} * 950 * 0.95=135.38 \mathrm{~L} / \mathrm{min} \\
\mathrm{P}_{0}=\mathrm{P} * \mathrm{q}=\frac{10 * 10^{6} * 135.38 * 10^{-3}}{60}=22.56 \mathrm{kw} \\
\mathrm{P}_{i}=\frac{\mathrm{P}_{0}}{\eta_{p}}=\frac{22.56}{0.9}=25.07 \mathrm{kw} \\
\mathrm{q}_{v}=135.38\left(\frac{\mathrm{L}}{\min }\right)=0.0023 \mathrm{~m}^{3} / \mathrm{s}
\end{gathered}
$$

$\mathrm{q}_{\mathrm{v}}$ is the actual flow rate of the hydraulic oil pump, $\mathrm{P}_{0}$ is the theoretical input power of the hydraulic pump with the motor, the indicated power of the Pi motor, and $\eta p$ is the indicated efficiency of the hydraulic pump motor.

\subsubsection{Calculation of pressure loss in pressurizing process of hydraulic oil pump, calculation of actual pressure on large piston and calculation of maximum pressure}

First, select the appropriate outside diameter of the pipe and calculate the flow rate inside the pipe.The outer diameter $\mathrm{D}=78 \mathrm{~mm}$, wall thickness $\mathrm{s}=23 \mathrm{~mm}$, and inner diameter $\mathrm{D}=32 \mathrm{~mm}$ have been selected for the hydraulic oil pump in front. Then, the flow velocity can be calculated according to the following formula to determine the flow state of oil in the pipe.

$$
\begin{gathered}
\mathrm{v}=\frac{\mathrm{q}_{\mathrm{v}}}{\mathrm{A}}=\frac{\mathrm{q}_{\mathrm{v}}=\mathrm{Av}}{\pi *\left(16 * 10^{-3}\right)^{2}}=2.86 \mathrm{~m} / \mathrm{s}
\end{gathered}
$$


Reynolds number Re is used to judge the flow state of pipeline.

$$
\operatorname{Re}=\mathrm{v} * \frac{\mathrm{d}}{\gamma}=2.86 * 16 * \frac{10^{-3}}{20 * 10^{-3}}=2288
$$

In the formula, $\mathrm{qv}$ is the actual flow rate of the hydraulic oil pump, m3/s, A is the cross-sectional area, $\mathrm{m} 2$, v refers to the flow velocity, $\mathrm{d}$ refers to the inner diameter, $\mathrm{m}$; $\gamma$ refers to the kinematic viscosity, and is found to be $20 * 10-3 \mathrm{~m} 2 / \mathrm{s}$ under the corresponding conditions. Reynolds number $\mathrm{Re}$ is 2288 , which can judge that the hydraulic oil in the tube belongs to laminar flow state [13].

As the inlet and outlet pipe diameter of the flow regulator is the same, fluid flow through the regulator only needs to consider local losses. The resistance coefficient varies with the valve opening, as shown in table 1 .

Table 1 Local resistance coefficient $(\varepsilon)$ table of flow regulating valve

\begin{tabular}{ccccccccccc}
\hline $\begin{array}{c}\text { The } \\
\text { open } \\
\text { ing }\end{array}$ & $\begin{array}{c}10 \\
\%\end{array}$ & $\begin{array}{c}20 \\
\%\end{array}$ & $\begin{array}{c}30 \\
\%\end{array}$ & $\begin{array}{c}40 \\
\%\end{array}$ & $\begin{array}{c}50 \\
\%\end{array}$ & $\begin{array}{c}60 \\
\%\end{array}$ & $\begin{array}{c}70 \\
\%\end{array}$ & $\begin{array}{c}80 \\
\%\end{array}$ & $\begin{array}{c}90 \\
\%\end{array}$ & $\begin{array}{c}100 \\
\%\end{array}$ \\
\hline$\varepsilon$ & 85 & 24 & 12 & 7.5 & 5.7 & 4.8 & $4 .$. & 4.1 & 4.0 & 3.9 \\
\hline
\end{tabular}

The local resistance of the reversing valve is $\varepsilon=3$

The flow state of the fluid from the round pipe is laminar, and the loss of resistance along the path can be calculated according to the formula (2).

$$
\Delta \mathrm{P}_{\lambda}=\lambda * \frac{\mathrm{L}}{\mathrm{d}} * \frac{\rho \mathrm{v}^{2}}{2}
$$

Where $\lambda$ is the resistance coefficient along the path, for the metal tube $\lambda=75 / \operatorname{Re}, \operatorname{Re}$ is the Reynolds number, $\Delta \mathrm{p} \lambda$ is the resistance loss along the path, $\mathrm{L}$ refers to the tube length, $\mathrm{m}, \mathrm{d}$ refers to the inner diameter of the tube, $\mathrm{m}, \rho$ refers to the density of the oil, $\mathrm{kg} / \mathrm{m} 3$, $\mathrm{v}$ refers to the flow rate, $\mathrm{m} / \mathrm{s}$.

According to the design flow figure 1, the hydraulic oil fluid flows through the three-stage pipeline. According to the design, the lengths of the three sections are $300 \mathrm{~mm}, 150 \mathrm{~mm}$ and $350 \mathrm{~mm}$ respectively, and the oil is found under the corresponding pressure and the density is $900 \mathrm{~kg} / \mathrm{m} 3$. Therefore, the pressure loss along the path is calculated according to formula (2):

$$
\begin{aligned}
\begin{aligned}
\Delta \mathrm{P}_{\lambda}=\lambda * \frac{\mathrm{L}}{\mathrm{d}} & \frac{\rho \mathrm{v}^{2}}{2}=\frac{75}{2288} *(300+150+350) * \frac{10^{-3}}{16 * 10^{-3}} * \frac{900 * 2.86}{2} \\
& =0.06 \mathrm{Mpa}
\end{aligned}
\end{aligned}
$$

When working, the flow regulating valve is fully open, so $\varepsilon$ throttle $=3.9, \varepsilon$ commutation $=3$, and the local resistance loss of the two valves is calculated according to formula (3):

$$
\Delta \mathrm{p}_{\varepsilon}=\varepsilon * \frac{\rho \mathrm{v}^{2}}{2}
$$

In the formula, $\Delta \mathrm{p} \varepsilon$ is the local resistance loss, $\varepsilon$ local resistance coefficient, and the rest is the same equation (2).

The local resistance loss calculated by substituting the data into equation (3) is as follows:

$$
\Delta \mathrm{p}_{\varepsilon}=\Delta \mathrm{p}_{\varepsilon 1}+\Delta \mathrm{p}_{\varepsilon 2}=\frac{3.9 * 900 * 2.86^{2}}{2}+\frac{3 * 900 * 2.86^{2}}{2}=0.025 \mathrm{Mpa}
$$

The total resistance loss is the resistance loss along the way plus the local resistance loss, namely:
$\Delta \mathrm{p}_{\text {total }}=\Delta \mathrm{p}_{\varepsilon}+\Delta \mathrm{P}_{\lambda}=0.06+0.025=0085 \mathrm{Mpa}$

The actual pressure at the inlet of the large piston is equal to the difference between the working pressure and the resistance loss of the hydraulic pump, namely:

$\mathrm{p}_{2}{ }^{\prime}=\mathrm{p}_{\text {fiuld }}-\Delta \mathrm{p}_{\text {total }}=10-0.0085=9.915 \mathrm{Mpa}$

Therefore, the maximum pressure that can be added to the high-pressure container through the pressurization lever is:

$$
\mathrm{P}_{\max }=\mathrm{p}_{2}^{\prime} *\left(\frac{\mathrm{S}_{2}}{\mathrm{~S}_{1}}\right)=9.915 * 25=247.88 \mathrm{Mpa}
$$

\subsubsection{Calculation of pushing speed of pressure rod and flow rate of ethanol into the ultra-high pressure reaction kettle}

Set the length of the pressurized cylinder as $1 \mathrm{~m}$, the diameter as $0.5 \mathrm{~m}$, the wide band of the large piston as $0.3 \mathrm{~m}$, and the diameter of the small piston as $0.1 \mathrm{~m}$. Calculate the volume of the pressurized cylinder, the volume occupied by the large piston and the flow rate of ethanol respectively:

$$
\begin{aligned}
& \mathrm{V}_{1}=\pi * \mathrm{r}_{1}{ }^{2} * 1=\pi * 0.25^{2} * 1=0.20 \mathrm{~m}^{3} \\
& \mathrm{~V}_{2}=\pi * \mathrm{r}_{1}{ }^{2} * 0.3=\pi * 0.25^{2} * 0.3=0.06 \mathrm{~m}^{3} \\
& \mathrm{~T}=\frac{\mathrm{V}_{1}-\mathrm{V}_{2}}{\mathrm{q}_{\mathrm{v}}}=\frac{0.20-0.06}{0.0023}=84 \mathrm{~s} \\
& \mathrm{qv}^{\prime}=\frac{\mathrm{V}_{3}}{\mathrm{~T}}=\frac{(1-0.3) * \pi * 0.05^{2}}{84}=6.54 * 10^{-5} \mathrm{~m}^{3} / \mathrm{s}
\end{aligned}
$$

$\mathrm{V}_{1}$ is the volume of the pressurized cylinder, $\mathrm{m}^{3}, \mathrm{~V}_{2}$ is the volume occupied by the large piston, $\mathrm{m}^{3}, \mathrm{~T}$ is the time when the booster rod is pushed from the leftmost to the right, and $\mathrm{s}, \mathrm{q}_{\mathrm{v}}$ ' is the flow rate of ethanol, $\mathrm{m}^{3} / \mathrm{s}$.

\subsubsection{Calculation of pushing speed of pressure rod and flow rate of ethanol into autoclave}

Set the length of the pressurized cylinder as $1 \mathrm{~m}$, the diameter as $0.5 \mathrm{~m}$, the wide band of the large piston as $0.3 \mathrm{~m}$, and the diameter of the small piston as $0.1 \mathrm{~m}$. Calculate the volume of the pressurized cylinder, the volume occupied by the large piston and the flow rate of ethanol respectively:

$$
\begin{aligned}
& \mathrm{V}_{1}=\pi * \mathrm{r}_{1}^{2} * 1=\pi * 0.25^{2} * 1=0.20 \mathrm{~m}^{3} \\
& \mathrm{~V}_{2}=\pi * \mathrm{r}_{1}^{2} * 0.3=\pi * 0.25^{2} * 0.3=0.06 \mathrm{~m}^{3} \\
& \mathrm{~T}=\frac{\mathrm{V}_{1}-\mathrm{V}_{2}}{\mathrm{q}_{\mathrm{v}}}=\frac{0.20-0.06}{0.0023}=84 \mathrm{~s} \\
& \mathrm{qv}^{\prime}=\frac{\mathrm{V}_{3}}{\mathrm{~T}}=\frac{(1-0.3) * \pi * 0.05^{2}}{84}=6.54 * 10^{-5} \mathrm{~m}^{3} / \mathrm{s}
\end{aligned}
$$

$\mathrm{V}_{1}$ is the volume of the pressurized cylinder, $\mathrm{m}^{3} ; \mathrm{V}_{2}$ are the volume occupied by the large piston, $\mathrm{m} 3 ; \mathrm{T}$ are the time when the pressurized rod is pushed from left to right once, $\mathrm{s} ; \mathrm{q}_{\mathrm{v}}$ 'are the flow rate of ethanol, $\mathrm{m}^{3} / \mathrm{s}$.

\subsubsection{Time required for the high pressure vessel to be added to the design pressure}


Set the volume of ethanol needed to fill the autoclave as $\mathrm{V} 3=20^{*} 10^{-3} \mathrm{~m}^{3}$, and calculate the time required to add to the design pressure:

$$
\mathrm{T}_{1}=\frac{\mathrm{V}_{3}}{\mathrm{q}_{\mathrm{v}}{ }^{\prime}}=\frac{20 * 10^{-3}}{6.54 * 10^{-5}}=305 \mathrm{~s}
$$

\subsubsection{Outlet velocity of pipe orifice during pressure relief of high-pressure vessels}

From Bernoulli's equation:

$$
\frac{\mathrm{P}_{1}}{\rho \mathrm{g}}+\frac{\rho \mathrm{v}_{1}{ }^{2}}{2}+\mathrm{z}_{1}=\frac{\mathrm{P}_{2}}{\rho \mathrm{g}}+\frac{\rho \mathrm{v}_{2}^{2}}{2}+\mathrm{z}_{2}
$$

Since $V_{1}$ is too small to be counted, the density of ethanol is calculated at $10^{3} \mathrm{~kg} / \mathrm{m}^{3}$,

$$
\text { And } \mathrm{z}_{1}=\mathrm{z}_{2} \text {, So: }
$$

$\frac{200 * 10^{6}}{10^{3} * 10}+0+\mathrm{z}_{1}=\frac{0.1 * 10^{6}}{10^{3} * 10}+\frac{10^{3} * \mathrm{v}_{2}^{2}}{2}+\mathrm{z}_{2}$,

The pressure relief velocity of ethanol liquid at the autoclave outlet was $\mathrm{v}_{2}=6.32 \mathrm{~m} / \mathrm{s}$.

\subsubsection{Calculation of hydraulic shock}

Calculation of hydraulic shock wave velocity [14] according to formula (4):

$$
\mathrm{C}=\frac{1000}{\sqrt{1+\frac{d}{\delta} * \frac{K}{E}}}=\frac{1000}{\sqrt{1+\frac{32 * 10^{-3}}{23 * 10^{-3}} *\left(\frac{900}{210000}\right)}}=997
$$

Where $\mathrm{d}$ refers to the inner diameter of the hydraulic system pipe, $\mathrm{m} ; \delta$ refers to the wall thickness of the hydraulic system pipe, $\mathrm{m}$; $\mathrm{K}$ refers to the bulk modulus of the hydraulic oil, Mpa; E refers to the elastic modulus of the pipe material, Mpa. Calculating the flow velocity $\mathrm{v}$ of the ethanol liquid in the tube according to the flow rate value qv of the ethanol and the cross-sectional area A of the pipe.

$$
\begin{aligned}
& q_{v}^{\prime}=A * v \\
& 0.000065=\pi *\left(16 * 10^{-3}\right)^{2} * \mathrm{v} \\
& \mathrm{v}=0.08 \mathrm{~m} / \mathrm{s}
\end{aligned}
$$

Maximum appreciation of impact pressure inside the hydraulic pipe:

$$
\Delta \mathrm{P}=\rho \mathrm{C} \mathrm{V}=900 * 997 * 0.08=0.0718 \mathrm{Mpa}
$$

\subsection{Strength check of ultrahigh pressure vessels [3]}

\subsubsection{Selection of ultra-autoclave materials}

Material selection: $40 \mathrm{CrNiMo}$ steel, high temperature resistance $850^{\circ} \mathrm{C} \sim 860^{\circ} \mathrm{C}$.

\subsubsection{Check cylinder size, design pressure and stress of each seal and connector}

The size of the cylinder: $\Phi 500 / 270$, designed to withstand pressure of $250 \mathrm{Mpa}, \mathrm{K}$ is the ratio of inner and outer diameter
$\mathrm{K}=\frac{500}{270}=1.85 \quad K^{2}=3.43$

The mechanical properties of materials are shown in table 2 .

Table2 Mechanical parameters of materials

\begin{tabular}{lllll}
\hline $\begin{array}{l}\text { Yield } \\
\text { strength } \\
\delta \mathrm{s}(\mathrm{Mpa})\end{array}$ & $\begin{array}{l}\text { Elongat- } \\
\text { ion }(\%)\end{array}$ & $\begin{array}{l}\text { Reduction } \\
\text { of area } \Psi \\
(\%)\end{array}$ & $\begin{array}{l}\text { Impact } \\
\text { toughness/a } \\
\mathrm{k}(\mathrm{J} / \mathrm{cm} 2)\end{array}$ & $\begin{array}{l}\text { Hardness } \\
/ \mathrm{HRC} \\
(\mathrm{HB})\end{array}$ \\
\hline 929 & 18.5 & 61.75 & 148 & 316 \\
\hline
\end{tabular}

After checking all kinds of pressure, all pipelines and joints under high pressure are in safe state. The design meets the requirements of equivalent stress, yield safety factor, yield pressure, blasting pressure safety factor and so on.

Through the design of the shoulder cover, the end cover connected with the clamp, the calculation of the opening, and the calculation of various kinds of stress, all meet the pressure requirements under the design conditions.

\subsection{Design and calculation of refrigeration system}

The cooling material is 80 liters according to the design requirement, and 20 liters of ethanol is needed to realize the quick-freezing function. Before work, pre-cool ethanol and material to $5^{\circ} \mathrm{C}$, and then cool ethanol and material to $-20^{\circ} \mathrm{C}$. According to the design scheme, R22 is used as refrigerant and ethanol as refrigerant carrier. Set refrigeration conditions: condensation temperature is $40^{\circ} \mathrm{C}$, evaporation temperature is $-40^{\circ} \mathrm{C}$, supercooling temperature is $35^{\circ} \mathrm{C}$, superheating temperature is $-35^{\circ} \mathrm{C}$. Through the thermodynamic calculation of the refrigeration system, a small compressor with a single machine and two stages was selected, with a cooling capacity of $35 \mathrm{~kW}$. There was a set of condenser with a cooling area of $10 \mathrm{~m}^{2}$ and an evaporating coil with an evaporation area of $10 \mathrm{~m}^{2}$. Other auxiliary equipment included a liquid storage device with a diameter of $80 \mathrm{~mm}$ and an oil separator with a diameter of $80 \mathrm{~mm}$, etc., which constituted all parts of the refrigeration system.

Calculate the cooling time of the food, use the ultrahigh pressure cooling instant freezing device, the cooling time required for the material to cool from $5^{\circ} \mathrm{C}$ to $-20^{\circ} \mathrm{C}$. During this period, the food is not frozen, the freezing is completed instantaneously during pressure relief, and the cooling time is calculated for $46 \mathrm{~min}$. If the same refrigerating system is used for conventional quickfreezing of food, the food will be frozen in the cold processing process. Then the cold processing time is $3.46 \mathrm{~h}$, which is much longer than the quick-cooling time of high-pressure quick-freezing.

\section{Comparative analysis of energy consumption}

The ultra-high pressure cooling and instantaneous freezing device adopts the matching use of hydraulic 
pump system and refrigeration system, and its energy consumption consists of two parts: the energy consumption of refrigeration system and the energy consumption of hydraulic system. But the traditional fast freezing only uses a set of refrigeration system, so its energy consumption only refrigeration system. First, it is assumed that the same cooling capacity is provided for ultra-high pressure cooling, instantaneous freezing and traditional quick-freezing, and the same cooling system is adopted. Through matching calculation, it can be known that the shaft power of the high-pressure compressor and the low-voltage compressor is 12.3 and $10.2 \mathrm{kw}$ respectively.

The shaft power of the hydraulic system pump is $22.56 \mathrm{kw}$.

Energy consumption of hydraulic system with ultrahigh pressure cooling and instantaneous freezing:

$$
\mathrm{E}_{1}=P_{0} * T_{1}=22.56 * 305=6880 \mathrm{~kJ}
$$

Using ultra-high pressure cooling and instantaneous freezing cooling system energy consumption:

$\mathrm{E}_{2}=\mathrm{P}_{\mathrm{eG}} * \mathrm{t}_{1}+\mathrm{P}_{\mathrm{eD}} * \mathrm{t}_{1}=12.3 * 2760+10.2 * 2760=62100 \mathrm{~kJ}$

Therefore, total energy consumption of ultra-high pressure cooling and instantaneous freezing:

$\mathrm{E}=E_{1}+E_{2}=6880+62100=68980 k \mathrm{~J}$

Energy consumption of traditional quick-freezing method:

$\mathrm{E}^{\prime}=\mathrm{P}_{\mathrm{eG}} * \mathrm{t}_{2}+\mathrm{P}_{\mathrm{eD}} * \mathrm{t}_{2}$

$=12.3 * 10^{3} * 12456+10.2 * 10^{3} * 12456$

$=280260 \mathrm{~kJ}$

$\mathrm{t}_{1}$ - processing time required by ultra-high pressure cooling and instant freezing, 46min $=2760 \mathrm{~s}$

$\mathrm{t}_{2}$ - the processing time required by traditional quickfreezing process is $3.46 \mathrm{~h}=12456 \mathrm{~s}$

$\mathrm{T}_{1}$ - time of pressure applied to hydraulic system $305 \mathrm{~s}$

Energy consumption ratio of ultra-high pressure cooling instantaneous freezing and traditional quick-freezing freezing processing:

$$
\frac{\mathrm{E}_{1}}{\mathrm{E}_{2}} * 100 \%=\frac{68980}{280260} * 100 \%=24.6 \%
$$

The energy consumption of ultra-high pressure cooling is only $24.6 \%$ of that of traditional quick-freezing.

\section{The conclusion}

The design idea of the ultra-high pressure instantaneous freezing device is put forward, which can realize rapid freezing in a very short time, and avoid the freezing unevenness, tissue structure damage or crack in freezing process caused by the difference of internal and external stresses of food. The device can use the principle of ultra-high pressure cooling and pressure relief freezing. After ultra-high pressure cooling, the food is immediately frozen to remove the pressure. In the design of hydraulic system, the device breaks through the limitation of traditional direct pressure ultra-high pressure design and avoids the disadvantages of small working capacity and unable to work continuously. Make full use of the principle of hydraulic transmission to realize low energy pressure transfer, realize continuous work under low energy consumption, greatly increase its effective working volume, improve the load capacity under unit energy consumption. In the process of cooling, forced convection heat transfer is carried out on the material by the flow of ethanol refrigerant liquid, which speeds up the cooling speed of the material. In the cooling process under ultra-high pressure, the food is not frozen, which reduces the time to reach the required freezing temperature and greatly improves the working efficiency. Compared with the atmospheric quickfreezing device with the same capacity, the energy consumption of the quick-freezing device using ultrahigh pressure cooling and instant freezing device for food freezing processing is only $24.6 \%$ of that of the atmospheric quick-freezing device. The development and application of the device not only solves the problem of storage of high-moisture and freeze-cracking food which is not suitable for traditional atmospheric pressure refrigeration, but also opens up a new way to improve the quick-frozen processing of meat, poultry and highquality nutrients. At the same time of maintaining its quality and original condition, it achieves better energy saving effect.

\section{Acknowledgement}

The authors would like to thank Shenzhen Science and Technology Innovation (NO.JCYJ20170306162116012) Committee providing the research project and the support of Guangdong (NO.2017A010104011) Science and Technology Department .

\section{References}

1. Z. Xu, B. Li, Q Luo, Pack. and food mach., 36, 63-67 (2018).

2. C. Lyu, G. Nastase, G. Ukpai, A. Serban, B. Rubinsky, X. Wang, Peer J. , 5, e3322 (2017).

3. D. Peng, J. Deng, X. Tan, M. Li, Prese. and process.., 9, 5-9 (2009).

4. Z. Guan, M. Li, X.Song, Food and ferment. indus., 33, 147-153 (2007).

5. Y. Cui, X. Xuan, X. Lin, Mod. Food Sci. Tech., 35, 32-39 (2019).

6. G. Zhou, H. Li, Q. Hu, Food indu. Tech., 30, 334336+339 (2009).

7. S. Wang, H. Xie, H. Su, Food sci., 33, 332-340 (2012).

8. W. M. Elamin, J. B. Endan , Y.A. Yosuf, J.Engin, Sci. Tech. Rev., 8, 75-83 (2015).

9. $\mathrm{S} \mathrm{Li}, \mathrm{Q}$. Wang, Classic design example of hydraulic system (Chemi. Tech. press, Beijing, 2016).

10. Y. Lin, J. Bao, H. Liu, Renew. Sustain. Ener. Rev., 50, 194-203 (2015).

11. G. Shao, Z. Wei, Ultrahigh pressure vessel (Chemi. Tech. press, Beijing, 2002). 
12. S. Wu, C. Chen, M. Jin, Inter. Combu. engine acces.,10, 182-183 (2019).

13. S. Yu, X. Song, G. Wang, Appl. Energ., 117, 14-20 (2019).

14. N. Li, Y.Zhang, J Wang, Mache. Tool \& Hydrau., 35, 149-151+192 (2007). 